\title{
On the Savings Wedge in International Capital Flows
}

\author{
Jacek Rothert \\ Department of Economics, U.S. Naval Academy, 589 McNair Rd, Annapolis, MD, e-mail: jacek.rothert@gmail.com
}

\begin{abstract}
I explore the determinants of the savings wedge in international capital flows computed in a sample of 68 developing countries in Gourinchas and Jeanne (2013). I show that size (rather than allocation) of net capital flows in the data is the major cause of the negative correlation between the calibrated savings wedge and productivity growth.
\end{abstract}

JEL codes: E21, F21, F41, F43

Keywords: allocation puzzle, savings wedge, capital flows

\section{Introduction}

Gourinchas and Jeanne (2013) (GJ henceforth) explored the patterns of capital flows in a sample of 68 developing countries. The study was motivated by the fact that a number of fast-growing developing countries (China, Hong-Kong, Singapore, Korea, Taiwan and Botswana) have experienced net outflows of capital. This is puzzling, because the workhorse small open economy growth model predicts net capital inflows to economies which are growing faster than the rest of the world.

The strongest result emphasized by the authors is the negative correlation (-0.97) between the average annual productivity growth and the "savings wedge": a reduced form distortion whose value for each country is chosen such that the benchmark neoclassical growth model with the wedge generates net capital flows equal to those in the data. The savings wedge acts like a tax/subsidy on savings. The negative correlation between such a tax and productivity growth means that countries which have been growing slowly tended to tax savings, in contrast to faster-growing countries that subsidized savings. The correlation is highly robust to exclusion of outliers such as the Asian tigers. GJ conclude that this negative correlation is key to understanding the "allocation puzzle".

In this letter, I explore the extent to which that correlation is driven by the size of net capital flows that we observe in the data, rather than their direction (or "allocation"). The answer is surprising: if we

Preprint submitted to Elsevier

April 29, 2016

(C) 2016. This manuscript version is made available under the Elsevier user license http://www.elsevier.com/open-access/userlicense/1.0/ 
exogenously limit the maximum size of net foreign asset position to empirically plausible levels, we can account for $80 \%$ of the cross-country variation in the savings wedge. We can also account for $65 \%$ of the range of values for the savings wedge computed by GJ.

What is the intuition? According to the neoclassical model, faster growing economies should borrow (a lot). To provide an example, from 1980 to 2000, Cyprus' productivity grew at an average rate of 5\% per year. During that period, the cumulative sum of net capital inflows equaled $50 \%$ of the country's 1980 Gross Domestic Product. When the same country is studied through the lens of the one-sector small open neoclassical economy (GJ benchmark), the predicted cumulative sum of net capital inflows equals 2000\% (two thousand percent) of the country's GDP in 1980. Hence, Cyprus has borrowed much less than the benchmark model predicts. On the opposite side of the spectrum, with average productivity growth of $-2 \%$, Venezuela had a cumulative sum of net capital inflows equal to $-25 \%$ of the country's GDP in 1980 . The neoclassical model would predict that number to be $-1000 \%$. It appears therefore that Venezuela (the slowgrowing economy) was taxing savings, while Cyprus (the fast-growing economy) was subsidizing savings. The savings wedges GJ estimate are $4.06 \%$ for Venezuela and $-3.74 \%$ for Cyprus.

My analysis proceeds as follows. First, I reproduce GJ's empirical findings using Penn World Table and IFS data, and explore the extent to which the negative (or zero) correlation between cumulative capital inflows and productivity growth are driven by few, albeit important, outliers. Second, given the robust negative correlation between the savings wedge and productivity growth, and the disparity between the predicted and actual size of net capital flows, I explore the link between the savings wedge and the size of net capital flows.

\section{Allocation Puzzle}

\subsection{Puzzling correlation}

Gourinchas and Jeanne (2013) study the long-term dynamics of net foreign asset position in a sample of 68 developing countries. First, they find a negative correlation between cumulative productivity growth and the cumulative capital inflows in the years 1980-2000. Figure 1 reproduces their main empirical findings. The left panel presents the scatter-plot of cumulative capital inflows and the cumulative catch-up in productivity

against the United States $\left(\frac{T F P_{2000} / T F P_{2000}^{U S A}}{T F P_{1980} / T F P_{1980}^{U S A}}-1\right)$. The correlation in the left panel is -0.4. The right panel presents the same data, but without foreign aid (also described by GJ). The correlation drops to -0.17 

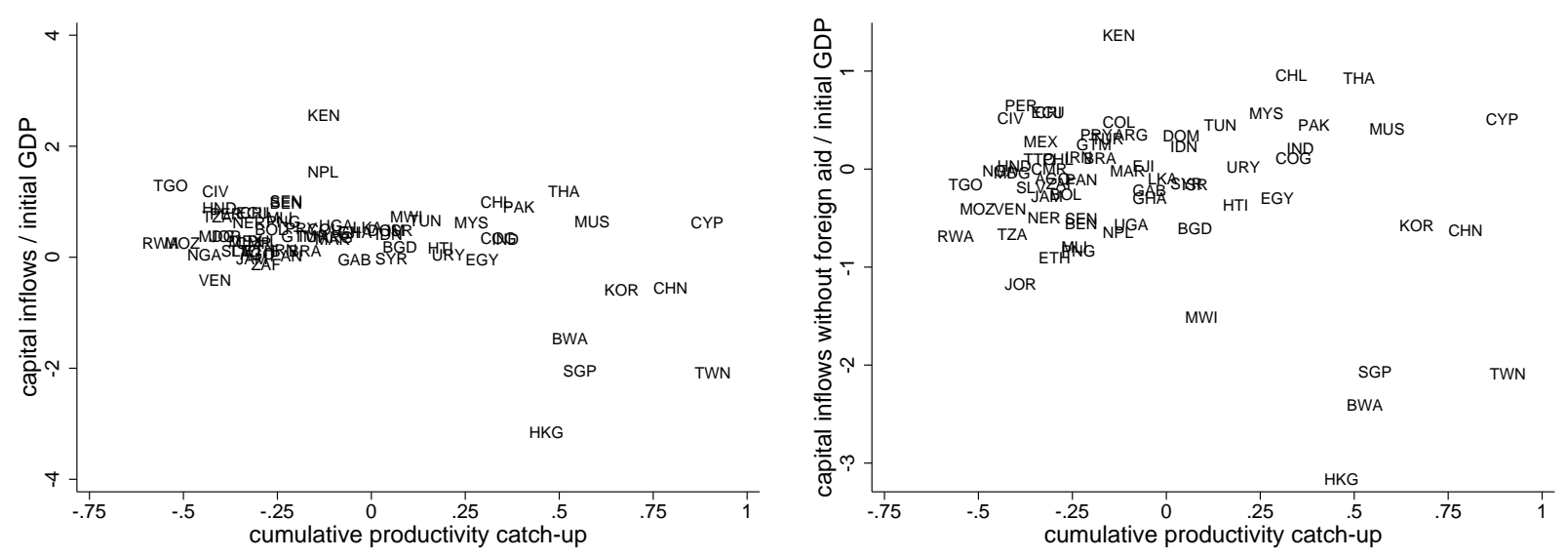

Figure 1: Allocation puzzle - redux

and is insignificant ${ }^{1}$. GJ conclude that capital inflows are at best uncorrelated with the growth rate of productivity, while economic theory predicts that higher productivity growth should be associated with larger capital inflows.

\subsubsection{Six drivers of the puzzling correlation?}

A closer look at the right panel of Figure 1 reveals that the lack of positive correlation in the data without foreign aid is driven by six (albeit important) outliers: China, Korea, Taiwan, Botswana, Hong-Kong and Singapore. If we remove these outliers and restrict the attention to the remaining 62 countries, the correlation becomes positive (30\%) and significant (see Figure 2).

\subsection{Savings wedge}

Next, GJ introduce a savings wedge into the standard neoclassical growth model. They calibrate it for each country by making sure the model generates the same change in external debt as we observe in the data (i.e. for each country they match its position in the left panel of Figure 1).

Neoclassical model with wedges. The planner's problem in the model with wedges is as follows:

$$
\max \sum_{t=1}^{\infty} \beta^{t} \frac{c_{t}^{1-\sigma}}{1-\sigma} N_{t}
$$

s.t.

$$
C_{t}+K_{t+1} \leq\left(1-\tau_{s}\right)\left(R_{t}\left(1-\tau_{k}\right) K_{t}-R^{*} D_{t}\right)+D_{t+1}+N_{t}\left(w_{t}+z_{t}\right)
$$

\footnotetext{
${ }^{1}$ Aguiar and Amador (2011) show the correlation reported in GJ is largely driven by public flows.
} 


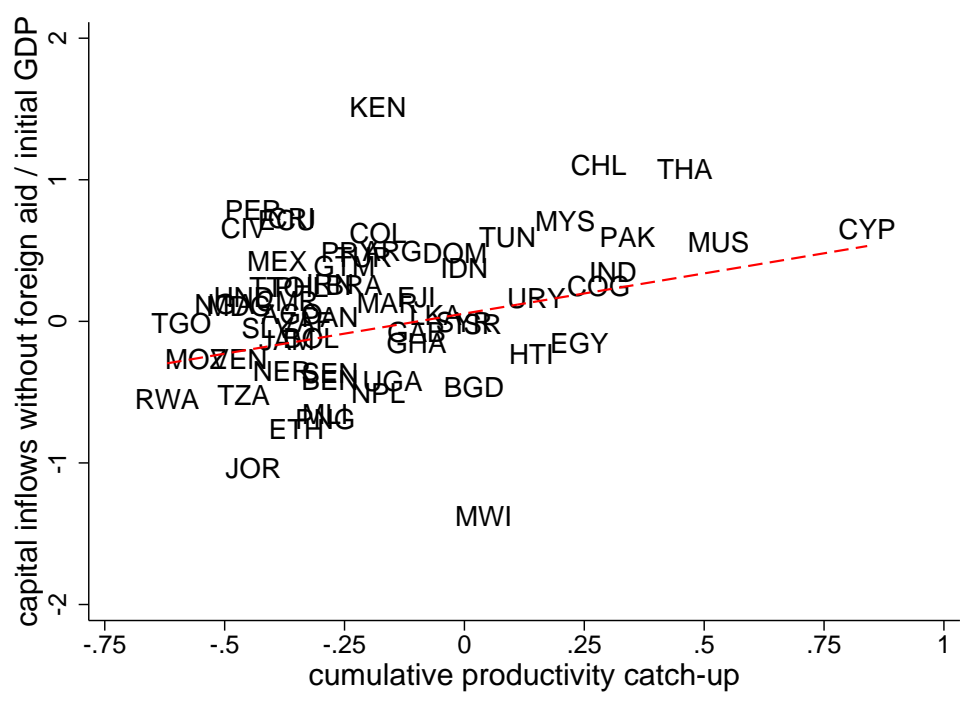

Figure 2: Net capital flows without foreign aid and without outliers

where $z_{t}=\tau_{k} R_{t} k_{t}+\tau_{s} R^{*}\left(k_{t}-d_{t}\right), \tau_{k}$ is the investment wedge. Production function is Cobb-Douglas: $G D P_{t}=K_{t}^{\alpha}\left(A_{t} N_{t}\right)^{1-\alpha}$. The inter-temporal Euler condition for this economy is:

$$
\left(\frac{c_{t+1}}{c_{t}}\right)^{\sigma}=\beta R^{*}\left(1-\tau_{s}\right)
$$

If $\tau_{s}>0$ then $\left(\frac{c_{t+1}}{c_{t}}\right)^{\sigma}<\beta R^{*}$ (which will be the case for slow-growing economies). If $\tau_{s}<0$ then $\left(\frac{c_{t+1}}{c_{t}}\right)^{\sigma}>\beta R^{*}$ (which will be the case for fast-growing economies). The investment wedge $\tau_{k}$ is calibrated for each country by matching average investment/GDP ratio. The savings wedge $\tau_{s}$ is calibrated to exactly match the change in net external debt. Figure 3 shows the relationship between the calibrated savings wedge and productivity catch-up. The result is striking: there is a strong and robust correlation of -0.97 .

\section{Understanding the savings wedge: size matters}

The lack of positive correlation between capital inflows and productivity catch-up is largely driven by the six outliers. The negative correlation between the savings wedge and productivity growth is definitely not. That correlation is -0.97 and is the strongest result in Gourinchas and Jeanne (2013): "the allocation puzzle is the savings puzzle" ${ }^{2}$. This section explores the extent to which the small net size of capital flows in the data accounts for such a strong correlation.

\footnotetext{
${ }^{2}$ Gourinchas and Jeanne (2013), page 21.
} 


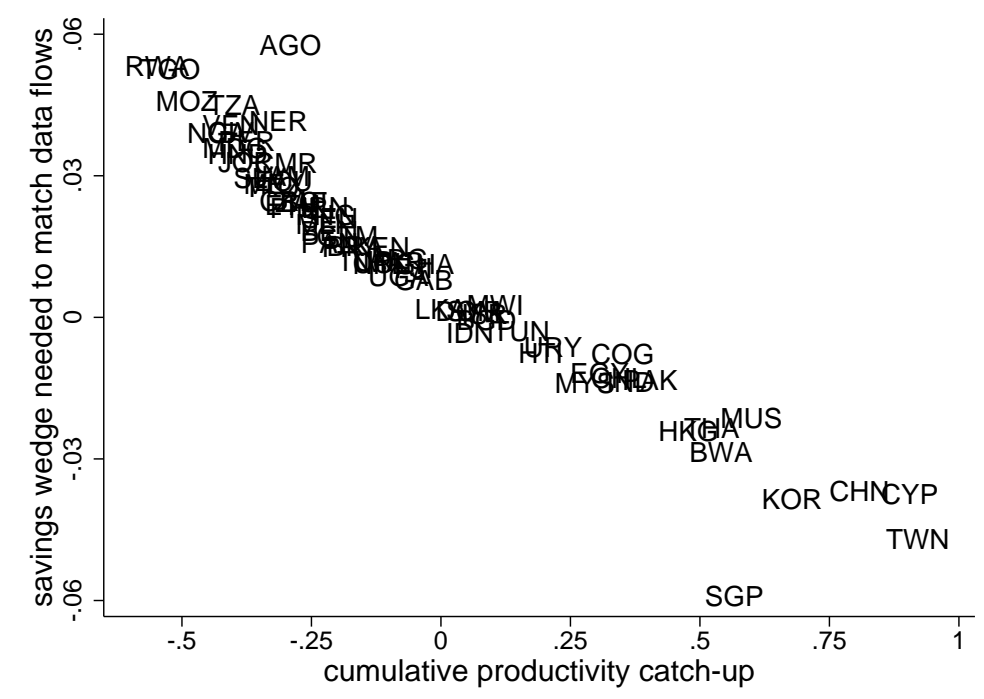

Figure 3: Allocation puzzle - redux

\subsection{Model with exogenous borrowing and saving requirements}

First I show that GJ's model with a savings wedge, as described in Section 2.2, is isomorphic to a neoclassical growth model with the time varying borrowing and savings requirements. The planner now must solve a slightly different problem:

$$
\max \sum_{t=1}^{\infty} \beta^{t} \frac{c_{t}^{1-\sigma}}{1-\sigma} N_{t}
$$

s.t.

$$
C_{t}+K_{t+1}=\left(R_{t}\left(1-\tau_{k}\right) K_{t}-R^{*} D_{t}\right)+D_{t+1}+N_{t}\left(w_{t}+z_{t}\right)
$$

$$
D_{t+1} \leq \bar{D}_{t}
$$

$$
\left(\underline{\lambda_{t}}\right) \quad D_{t+1} \geq \underline{D}_{t}
$$

The only difference between this model and the one in Section 2.2 is that instead of the savings wedge, there are borrowing/savings constraints: (3.2), and (3.3). In each period, there is a potentially different lower (upper) bound on net external debt: $\underline{D}_{t}\left(\bar{D}_{t}\right)$, and for every $t$ we have $\underline{D}_{t}<\bar{D}_{t}$. The Lagrange multipliers on the two constraints are $\overline{\lambda_{t}}$ and $\underline{\lambda_{t}}$. The Euler equation for international borrowing and lending reads:

$$
\left(\frac{c_{t+1}}{c_{t}}\right)^{\sigma}=\beta R^{*}+\frac{\overline{\lambda_{t}}}{\beta^{t} U_{c, t+1}}-\frac{\frac{\lambda_{t}}{\beta^{t} U_{c, t+1}}}{{ }^{\prime}}
$$




\begin{tabular}{lcc}
\hline \hline & $\begin{array}{c}\text { Right hand side of }(2.1) \text { and }(3.4) \\
\text { Catching-up }\end{array}$ & Falling-behind \\
\hline $\begin{array}{l}\text { model } \\
\text { w } / \text { savings } \\
\text { wedge }\end{array}$ & $\beta R^{*}\left(1-\tau_{s}\right)>\beta R^{*}$ & $\beta R^{*}\left(1-\tau_{s}\right)<\beta R^{*}$ \\
\hline & $\left(\tau_{s}<0\right)$ & $\left(\tau_{s}>0\right)$ \\
\hline $\begin{array}{l}\text { model w/ } \\
\text { limits on net } \\
\text { borrowing/saving }\end{array}$ & $\left(\right.$ only $\overline{\lambda_{t}}>0$ for some $\left.t\right)$ & $\left(\right.$ only $\underline{\lambda_{t}}>0$ for some $\left.t\right)$ \\
\hline
\end{tabular}

Table 1: Mechanics of savings wedge and limits on borrowing/lending

For a fast-growing economy, only (3.2) will ever be binding (i.e. only $\overline{\lambda_{t}}>0$ for some $t$ ). For a slow-growing economy, only (3.3) will ever be binding (i.e. only $\overline{\lambda_{t}}<0$ for some $t$ ). As Table 1 shows, this is isomorphic to the model with $\tau_{s}<0$ in fast-growers, and with $\tau_{s}>0$ in slow-growers.

\subsection{Quantitative Evaluation}

It is not clear what fraction of the savings wedge (and its correlation with the productivity growth) we can account for by simply limiting net capital flows to the magnitudes observed in the data. I will now address this issue.

First, I consider a model from Section 3.1, i.e. the neoclassical growth model with exogenously imposed limits on the international borrowing and lending (3.2)-(3.3). The limits are common for all economies and constant over time $\left(\underline{D}_{t}=\underline{D}\right.$ and $\bar{D}_{t}=\bar{D}$, all $\left.t\right)$. For each economy, I simulate capital flows predicted by such calibrated model. I treat these predicted flows as the data, and look at them through the lens of the GJ framework. Lastly, I compare the savings wedges they would have obtained using such model-generated data, with the wedges they obtained using actual data.

Calibration and parameter values. Initial TFP is normalized to one: $A_{0}=1$. Both $\underline{D}$ and $\bar{D}$ are calibrated so that the model generates the same range of values for $\Delta D / Y_{0}$ as we observe in the data: $-3.15 \leq \Delta D / Y_{0} \leq$ 2.55 (see the Y-axis in Figure 1). This yields $\underline{D}=0.6$, and $\bar{D}=0.75$. The remaining parameters are identical to the ones used in Gourinchas and Jeanne (2013): $\beta=0.96$, capital share $\alpha=0.30$, utility function is $\log (C)$ so $\sigma=1$, and depreciation rate is $\delta=0.06$.

Results. The main result is presented in Figure 4. The figure shows a scatter-plot of the two savings wedges: the X-axis shows the savings wedge that GJ computed when they studied actual data $\left(\tau_{s}(\right.$ data $\left.)\right)$; the Y-axis 


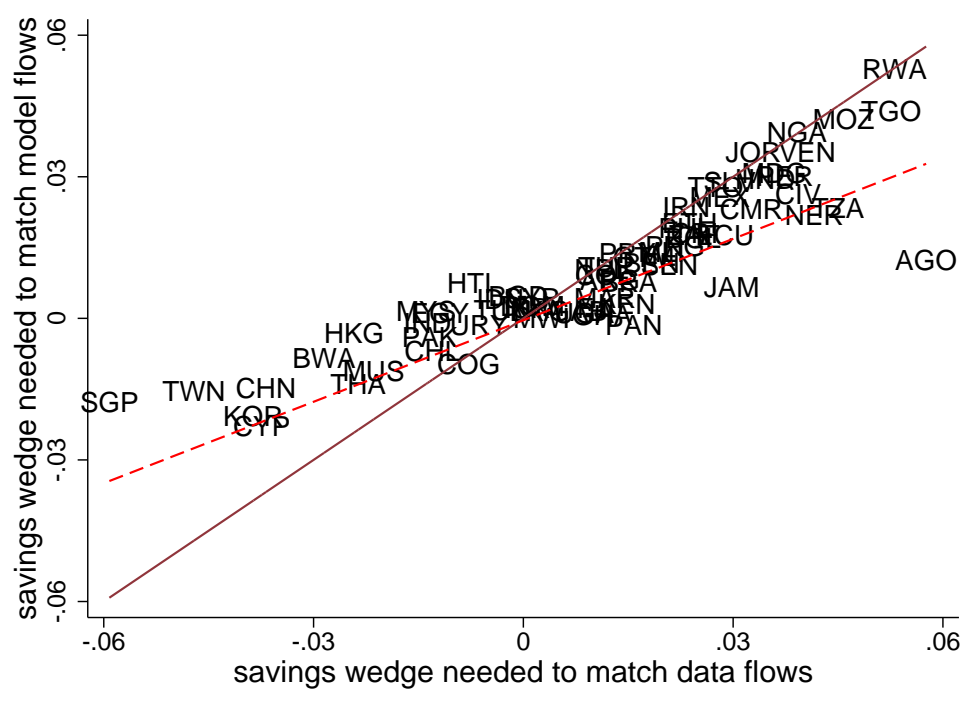

Figure 4: Savings wedge: $\tau_{s}($ data $)$ vs. $\tau_{s}($ model $)$

X-axis: savings wedge computed in Gourinchas and Jeanne (2013) using actual data $\left(\tau_{s}(\right.$ data $)$ )

Y-axis: savings wedge that would have been computed using model-generated data $\left(\tau_{s}(\right.$ model $\left.)\right)$

Solid line: 45 degree line; Dashed line: linear fit $\left(R^{2}=0.80\right)$.

shows the savings wedge that GJ would have computed had they studied the artificial data generated by the calibrated model from Section $3.1\left(\tau_{s}(\right.$ model $\left.)\right)$. The correlation between the two wedges is $89 \%$, implying that the model accounts for $80 \%$ of the cross-country variation in the savings wedge. The result on its own would not be important if the model were not also successful in matching the range of values for the savings wedge reported by GJ. The range computed in GJ is $[-5.9 \%, 5.8 \%]$. The range for $\tau_{s}($ model $)$ is $[-2.7 \%, 4.9 \%]$, which accounts for $65 \%$ of the range in GJ $\left(\frac{|0.049-(-0.027)|}{|0.058-(-0.059)|}=0.65\right)$.

\subsection{Why are net capital flows so small?}

It's important to emphasize that the goal of this letter was only to evaluate the extent to which the savings wedge in GJ is driven by size of net capital flows. Understanding the reasons behind the small size of net flows requires further analysis. It can result from financial frictions and lack of insurance (Bai and Zhang (2010), Carroll and Jeanne (2009)). It can be a result of government policies (Michaud and Rothert (2014)). It can also be a manifestation of fundamentals: (i) the existence of a non-tradable component in both consumption and investment (Rothert and Short (2014), Stockman and Tesar (1995)), or (ii) habit formation in consumption (Carroll et al. (2000)). 


\section{Summary}

The fact that some fast-growing countries have accumulated large net external surpluses is puzzling. The key to understanding this puzzle is to understand the factors that drive down autarky interest rate in those countries. The negative correlation between the savings wedge and productivity has to do with something else - the size of net capital flows, which are much smaller than the neoclassical model predicts. Understanding this discrepancy may require understanding the factors that reduce the interest-elasticity of countries' savings supply and investment demand.

\section{Acknowledgments}

I thank Katherine Smith and Jacob Short for their helpful comments and conversations. All errors are mine. The views expressed herein are my own and do not necessarily represent the views of the Department of Defense.

\section{References}

Aguiar, Mark and Manuel Amador, "Growth in the Shadow of Expropriation," The Quarterly Journal of Economics, 2011, 126 (2), 651-697.

Bai, Yan and Jing Zhang, "Solving the Feldstein-Horioka Puzzle With Financial Frictions," Econometrica, $032010,78(2), 603-632$.

Carroll, Christopher D. and Olivier Jeanne, "A Tractable Model of Precautionary Reserves, Net Foreign Assets, or Sovereign Wealth Funds," NBER Working Papers 15228, National Bureau of Economic Research, Inc August 2009.

_ , Jody Overland, and David N. Weil, "Saving and Growth with Habit Formation," American Economic Review, June 2000, 90 (3), 341-355.

Gourinchas, Pierre-Olivier and Olivier Jeanne, "Capital Flows to Developing Countries: The Allocation Puzzle," Review of Economic Studies, 2013, 80 (4), 1484-1515.

Michaud, Amanda and Jacek Rothert, "Optimal borrowing constraints and growth in a small open economy," Journal of International Economics, 2014, 94 (2), 326-340. 
Rothert, Jacek and Jacob Short, "Non-Traded Goods, Structural Change, and Capital Flows to Developing Countries," Departmental Working Papers 47, United States Naval Academy Department of Economics March 2014.

Stockman, Alan C and Linda L Tesar, "Tastes and Technology in a Two-Country Model of the Business Cycle: Explaining International Comovements," American Economic Review, March 1995, 85 (1), 168-85. 